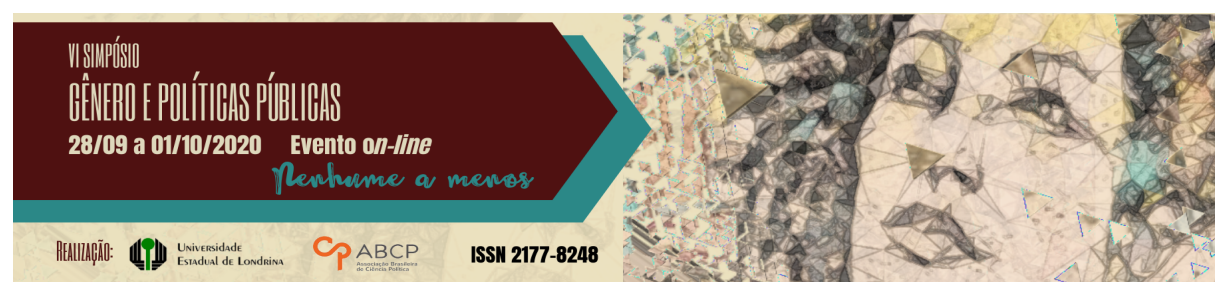

\title{
Maria o exemplo a ser seguido: a imagem feminina nas práticas culturais católicas no Hallel em Maringá-PR
}

\author{
Mariane Rosa Emerenciano da Silva1; ${ }^{1}$ Vanda Fortuna Serafim²
}

\section{Resumo}

Esse artigo é um desdobramento da pesquisa de mestrado "Catolicismo e Juventude: A História do Hallel em Maringá- PR (1995-2019)". Considerando que o Hallel é um movimento leigo de música católico, que reúne diversas frentes da Igreja católica num final de semana no Parque de Exposições Francisco Feio Ribeiro, com atividades expostas em módulos, que são os locais montados para apresentarem músicas, pregações, teatros, etc. E que nesses locais há um trânsito de pessoas que busca uma vivência religiosa, aqui buscamos tecer algumas considerações sobre a imagem de Maria como modelo de conduta católica, além de observarmos que devoção mariana é uma forte característica no catolicismo brasileiro.

Palavras-chave: catolicismo; Maria; feminino; devoção.

O Hallel é um evento de música que começou a ser organizado em Franca-SP, no ano de 1988. Naquela época há indicativos que Maria Theodora Lemos Silveira, conhecida como tia Lolita inspirou-se no Rock in Rio (1985), para organizar um evento onde jovens pudessem por meio da música louvar e adorar a Deus. Essa também pensava em como realizar um evento em comemoração aos 10 anos da Renovação Carismática Católica (RCC) naquela cidade, assim o Hallel tem

\footnotetext{
${ }^{1}$ Mestranda em História pela Universidade Estadual de Maringá (PPH/UEM), pela linha de "História, Cultura e Narrativas". E-mail: marianer.emerenciano@gmail.com ${ }^{2}$ Doutora em História pela UFSC. Professora adjunta no Departamento de História da Universidade Estadual de Maringá e no Programa de Pós-graduação em História (PPH/UEM). E-mail: vandaserafim@gmail.com
}

GT 10 - Gênero e religiosidades 
vertentes de um catolicismo carismático (SILVEIRA, 2007, p.13). A partir de 1995 outras cidades são chamadas a organizar o evento, com influência da Evangelização 2000, uma campanha da Igreja católica que buscava novos métodos e abordagens de evangelização. Maringá foi uma das cidades convidadas a realizar o evento, por meio de um grupo de leigos chamado Projeto Mais Vida, que é uma organização que realiza acampamentos religiosos, ações sociais, missas e encontros desde 1992 e pertencem a Arquidiocese de Maringá.

O evento em Maringá geralmente ocorre em dois dias, sábado e domingo. De 1995 a 2019 houve 25 edições na cidade ${ }^{3}$. Nesses dois dias de evento, várias pastorais, grupos de leigos e outras frentes da Igreja católica expõe no local suas atividades, como exemplo, citamos os Vicentinos, o Movimento Familiar Cristão, o Projeto Mais Vida, Renovação Carismática, Infância Adolescência Missionária (IAM), cantores e artistas, como Tiago Brado, Colo de Deus, Rosa de Saron, Anjos de Resgate, ou ainda, padres como, pe. Marcelo, pe. Reginaldo Manzotti. O evento ainda conta com o apoio da Arquidiocese de Maringá, que tem celebrações dos cultos Eucarísticos por meio dos padres e arcebispo da cidade Dom Anuar Battisti (2004-2019)4 Desse modo, é possível observar vários módulos que podem ser: Módulo da Família, Módulo Pregadores, Módulo Namoro, Módulo Maria, Módulo

\footnotetext{
3 As datas das edições do Hallel em Maringá de 1995 a 2019 foram as seguintes: 1995, $1^{\circ}$ HALLEL: 30 de julho; 1996, $2^{\circ}$ HALLEL: 14 de julho; 1997, $3^{\circ}$ HALLEL: 20 julho; 1998, $4^{\circ}$ HALLEL: 06 de setembro; 1999, $5^{\circ}$ HALLEL: 05 de setembro; 2000, $6^{\circ}$ HALLEL: 03 setembro; 2001, $7^{\circ}$ HALLEL: 02 setembro; 2002, $8^{\circ}$ HALLEL: 2003, $9^{\circ}$ HALLEL: 06 e 07 de setembro; 2004, $10^{\circ}$ HALLEL: 04 e 05 de setembro; 2005, 11 ${ }^{\circ}$ HALLEL: 03 e 04 de

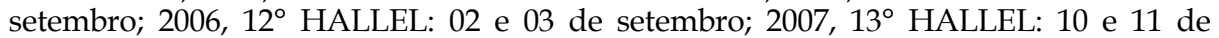
novembro; 2008, $14^{\circ}$ HALLEL: 08 e 09 de novembro; 2009, 15 ${ }^{\circ}$ HALLEL: 07 a 08 de novembro; 2010, 16 $6^{\circ}$ HALLEL: 13 e 14 de novembro; 2011, 17 HALLEL: 05 e 06 de novembro; 2012, $18^{\circ}$ HALLEL: 03 e 04 de novembro; 2013, 19 HALLEL: 09 e 10 de novembro; 2014, 20 $0^{\circ}$ HALLEL: 08 e 09 de novembro; 2015, $21^{\circ}$ HALLEL: 07 e 08 de novembro; 2016, $22^{\circ}$ HALLEL: 03 e 04 de dezembro; 2017, $23^{\circ}$ HALLEL: 04 e 05 de novembro; 2018, 24 $4^{\circ}$ HALLEL: 29 e 30 de setembro; 2019, 25 HALLEL: 05 e 06 de outubro.

4 Durante a pesquisa é possível afirmar que todos os arcebispos que passaram pela Arquidiocese até 2019 apoiaram a realização do evento: Dom Jaime (1957-1997); Dom Murilo Krieger (1997-2002); Dom Braz de Aviz (2002-2004) e Dom Anuar Battisti (20042019).
} 
Jovem, Palco Central, Hallelzinho, Módulo RCC, Módulo Arte, Capela do Silêncio, Capela do Louvor, entre outros.

Com um público majoritariamente jovem (entre 16-25 anos) e católico, podemos dizer que o grande chamariz para essa juventude são as perspectivas de um catolicismo menos tradicional, no qual, são em grande medida atraídos pelos shows. Enfatizamos ainda, que por parte da instituição e dos organizadores o Hallel é uma festa de culto eucarístico, ou seja, do culto ao corpo e sangue de Cristo por meio da Eucaristia, desse modo, percebemos que no Palco Central as atividades do evento tem início com a missa e encerram com a Benção do Santíssimo, ambos rituais que celebram o corpo sacramentado de Cristo. Todavia, o que não nos escapa aos olhos é a presença da imagem de Maria, mãe de Jesus Cristo.

Ali naquele evento, local de diversas formas de orações, de diversos temas, podemos observar a presença do modelo de feminino. Maria está na música cantada pelos artistas, nas palestras sobre família, é a intercessora para realizar pedidos. Está nas camisetas de alguns participantes, nos terços carregados por algumas pessoas em suas mãos, pescoço ou no cós da calça. Possuí um espaço voltado apenas a ela, o Módulo Maria. Nesse sentido, temos como maior enfoque abordar nossas percepções durante a pesquisa de campo realizada entre os anos de 2014-2019, com intuito de compreender a devoção a Maria nessa festa em Maringá, não esquecendo que ao se tratar de uma figura exemplar para os católicos ela inspira concepções de conduta feminina.

\section{Devoções marianas}

Solange Ramos de Andrade em Devoções e santuários Marianos na História do Paraná publicado no ano 2012, aponta que a religiosidade católica no Brasil é fortemente ancorada na imagem da Virgem Maria, no papel de mãe e protetora. No Paraná, de trezentos e noventa e nove munícipios, cento e sessenta e quatro possuem como Padroeiras e múltiplas devoções marianas (ANDRADE, 2012). Dentre essas cidades 
Maringá é uma delas, com a padroeira Nossa Senhora da Glória, festejada no dia 15 de agosto. Um dos maiores monumentos da cidade a Catedral, leva o nome de Basílica Menor ${ }^{5}$ Nossa Senhora da Glória6, local central e privilegiado na cidade. No que concerne as devoções marianas Andrade (2012) se atenta ao seguinte:

As devoções marianas chegaram ao Brasil com os portugueses no contexto da colonização e conseqüente processo de evangelização. Símbolo de uma religiosidade fortemente ancorada no papel da mãe protetora, que em determinados períodos 'aparece' para alertar seus devotos acerca dos perigos do mundo, esta devoção foi apropriada pela autoridade eclesiástica e sua necessidade de apresentar uma memória oficial em sintonia com um projeto de purificação e controle das devoções consideradas impróprias (ANDRADE, 2012, p. 241).

Nesse sentido, a devoção mariana trazida pelos portugueses, possuí duas características marcantes segundo Andrade (2012), uma é a "devocional" e a outra "institucional". O "catolicismo devocional" é composto por novenas, reza de terços, milagres, os cultos aos santos e aparições marianas, essas práticas escapam as instituições, elas ocorrem por meio de uma relação íntima do devoto com o sagrado. Já o "catolicismo institucional" é controlado pela hierarquia eclesiástica, e concerne nas celebrações de eucarísticas, os sacramentos, dogmas, aprofundamentos teológicos, no que tange Maria é a figura padroeira das cidades e dá o nome as várias paroquias, (ANDRADE, 2012, p. 242) tal como mencionamos sobre a Catedral de Maringá. Tanto o

\footnotetext{
5 A Catedral começou a ser construída em 1958 e terminou em 1972. Segundo Jonas Jorge da Silva (2011), “O título de Basílica Menor foi dado em 1982. Basílica Menor é um título honorífico concedido para um templo pelo Papa, seja pelo seu valor histórico, pelo fluxo e devoção de fiéis em seu interior ou pela beleza artística da obra. No caso da Catedral de Maringá, é bem provável que o último elemento tenha sido um dos motivos do reconhecimento papal". (SILVA, 2011, p. 89).

6 "Durante o período que antecedeu a criação da Diocese de Maringá, antes de ser Catedral, a Igreja era a sede da Paróquia Santíssima Trindade, criada em 18 de abril de 1950. Depois, mais especificamente em 15 de agosto de 1953, passou a se chamar Paróquia Nossa Senhora da Glória, denominação conferida pelo então bispo de Jacarezinho, dom Geraldo de Proença Sigaud, numa menção ao dogma católico da Assunção de Maria ao céu, em corpo e alma" (SILVA, 2011, p. 71).
} 
catolicismo "devocional" quanto o "institucional" não são formas que se encontram separadas. Elas convivem concomitantemente, numa troca, no qual por parte institucional há uma legitimação dessas devoções, mas que não se atém a ela, pois diz respeito justamente ao contato lúdico dos devotos.

Destarte, a devoção e a instituição mostram suas faces no em Maringá, além da Catedral, os movimentos leigos são marcados pela devoção mariana. Com as Congregações Marianas7, o Movimento

7 “As Congregações Marianas tiveram início em 1563, quando o jesuíta Pe. Jean Leunis começou, entre os alunos do Colégio Romano, em Roma, um sodalício (grupo) cujos membros se distinguiam por uma vida cristã e mariana fervorosa e pela prática de diversas formas de apostolado. [...] No Brasil, as Congregações Marianas existiram no período colonial, sobretudo nos Colégios da Companhia de Jesus e praticamente desapareceram com a expulsão dos jesuítas, em 1759. [...] Em maio de 1988, o Conselho Mundial das Comunidades de Vida Cristã, mantendo o reconhecimento das Congregações Marianas no Brasil, admitiu também a representação, naquele Conselho, das primeiras Comunidades de Vida Cristã que, como tais, já começavam a existir no País. Criou-se assim, uma dupla presença do Brasil naquele Conselho Mundial, através de associações que funcionam completamente independentes uma da outra. Tal situação levou as Congregações Marianas do Brasil, na sua Assembléia Nacional realizada em novembro de 1991, em Aparecida, estado de São Paulo, a aprovar um novo Estatuto da Confederação Nacional, no qual há uma referência explícita a uma Regra de Vida a ser elaborada, a qual, substituindo em âmbito de Brasil, os Princípios Gerais e as Normas Gerais, fizesse das Congregações Marianas do Brasil uma associação religiosa de leigos, autônoma, com a marca característica da devoção mariana, como sempre foram e continuaram sendo no Brasil. Esta decisão teve aprovação do Assistente Eclesiástico Nacional das Congregações Marianas, o Arcebispo do Rio de Janeiro, Cardeal Dom Eugênio Sales. Os Congregados Marianos do Brasil podem ser reconhecidos nas reuniões ou celebrações da Igreja pela fita que pende do pescoço da cor azul (cor litúrgica da Virgem Maria), em cuja extremidade está uma medalha prateada com a imagem do Nosso Senhor Jesus Cristo de um lado, de outro a da Mãe Santíssima, a Virgem Maria". CNCMB. Quem somos. Disponível em: https://cncmb.org.br/quem-somos. Acesso em: 28/08/2020. 
postólico de Schoenstatt ${ }^{8}$, Equipes de Nossa Senhora9 ${ }^{9}$ regulamentados pela Arquidiocese ${ }^{10}$. Além de grupos que possuem um forte aparato devocional em Maria como é o caso da Renovação Carismática Católica (RCC). Destacamos esse último grupo, principalmente quando percebemos os usos históricos de Maria enquanto uma crença de manutenção do catolicismo e luta contra os infiéis.

Senhora dos mares, rainha da paz e da guerra, durante as cruzadas ajudara os cristãos na luta contra os infiéis e continuaria atuando nas guerras santas

8 "O Movimento Apostólico de Schoenstatt pertence à Igreja Católica Apostólica Romana e faz parte da Obra Internacional fundada em 18 de outubro de 1914, pelo Pe. José Kentenich, em Schoenstatt, na Alemanha. Schoenstatt - cuja palavra significa belo lugar - é o bairro da cidade de Vallendar, às margens do Rio Reno, onde estava localizado o seminário dos padres Palotinos". O movimento conta a seguinte história sobre si: "Nos primeiros anos da Fundação, durante a I Guerra Mundial, muitos seminaristas foram convocados como soldados e, apesar dos desafios, difundiram a espiritualidade de Schoenstatt entre soldados e enfermeiros da guerra. Em poucos anos a Mãe de Deus atraiu muitas pessoas ao Santuário, realizando milagres de conversão e transformações nas almas. Em 1919, o grande número de leigos vinculados a Schoenstatt, leva à fundação da União Apostólica de Schoenstatt. A década de 1920 foi marcada pela entrada das mulheres: a fundação da União Apostólica Feminina, em 1920, e o Instituto Secular das Irmãs de Maria de Schoenstatt, em 1926. O sacrifício de vida dos primeiros schoenstattianos fez jorrar abundantes graças e rapidamente surgiram outros ramos no Movimento. Na década de 1930, surge a Juventude Feminina e a Obra se expande para outros continentes: as Irmãs de Maria são enviadas como missionárias para a África e a América do Sul. [...] A Campanha da Mãe Peregrina de Schoenstatt surge em 10 de setembro de 1950 e acelera a expansão do Movimento em todo o mundo e aprofunda a sua inserção nas paróquias e dioceses do Brasil". SCHOENSTATT.

Disponível

em:

https://schoenstatt.org.br/home/quem_somos/quem/expansao-do-movimento-deschoenstatt/. Acesso em: 28/08/2020. Schoenstatt

9 Tem origem em Paris no ano de 1938, pelo padre Henri Caffarel que atende um casal como guia espiritual. Movimento de espiritualidade conjugal católico, leigo e constituído por casais que buscam no sacramento do matrimônio um ideal de vivência cristã. Se reúnem: "em Equipes sob a proteção de Nossa Senhora e através de pontos concretos de esforço procuramos progredir, como casal, família, no amor de Deus e do próximo. Uma equipe não pode viver isolada. O Movimento das Equipes de Nossa Senhora possui uma organização destinada a coordenar, animar, apoiar, servir e manter a sua unidade. Essa unidade é constituída e formada pelo desejo de progredir juntos na fidelidade ao espírito e aos seus métodos". ENS. Quem somos. Disponível em: https://www.ens.org.br/novo/o-movimento/organizacao. Acesso. 28/08/2020.

10 Essas foram informações encontradas no site da Arquidiocese Maringá sobre as pastorais e organismos da mesma. Não contempla os mais diversos grupos de orações e comunidades que derivam desses organismos e/ou de outras pastorais e organismos. Vide: ARQUIOCESE DE MARINGÁ. Disponível em: http://arquidiocesedemaringa.org.br/pastorais. Acesso em: 27/08/2020. 
entre católicos e protestantes. Mas, se no contexto da Reforma católica sua imagem e força estavam ainda ligadas à sua presença e intervenção nas batalhas, o espírito contra-reformista encontraria eco em uma devoção que, como pretendo sugerir, punha em relevo questões importantes para a Igreja Católica. Refiro-me à devoção ao rosário, método de oração e meditação ensinado, segundo a tradição, pela Virgem Maria e para seu louvor (ANDRADE, 2012, p. 247).

São duas questões apresentadas por Andrade (2012) a primeira sobre a luta contra os infiéis nos leva a considerar a afirmativa de Reginaldo Prandi (1998) ao pontuar que o movimento da RCC que surge como enfrentamento do pentecostalismo protestante na segunda metade do século XX, tem Maria como identidade religiosa “Muitos [...] identificam-se com a Renovação Carismática pela possibilidade de se ter, ao mesmo tempo, o Espírito Santo e Nossa Senhora: pentecostalismo sim, mas com Maria" (PRANDI, 1998, p. 137-138). O autor ainda reforça, "Para os católicos é a Santa Mãe de Jesus, da Igreja e de todos os cristãos, digna de todos os louvores; para os protestantes, uma mulher que recebeu uma graça especial e que deve ser lembrada como um exemplo de conduta, não mais" (PRANDI, 1998, p. 139). "[...] os carismáticos fomentam o culto a Nossa Senhora, colocando-a como premissa insubstituível na salvação dos homens" (PRANDI, 1998, p. 139).

A segunda questão, sobre a devoção do rosário fora na cidade de Maringá foi observada por nós proximidade por meio do Projeto Mais Vida, que ao constituir comunidades formadas por pessoas que participam a cada edição do acampamento se reúnem para a oração do terço, na casa de membros que pertencem a essas comunidades. Já ao nos referirmos sobre o Hallel, prioritariamente o Módulo de Maria realiza os terços meditados. Entretanto, em algumas edições do Hallel como em 2019 e 2018 houve a prática dessa devoção no Palco Central (2019) em homenagem a Nossa Senhora de Guadalupe, a pedido de tia Lolita, a fundadora do Hallel, e em 2018 no Módulo Família. Mesmo para aqueles que não possuem a prática de orar o terço, podemos dizer 
que são essas contas que possuem uma forte representatividade da identificação católica, no evento víamos locais que vendiam tais objetos, víamos entrelaçados nas mãos de alguns participantes, pendurado no cós da calça, ou em seus pescoços.

É necessário ressaltar que a existência desses movimentos marianos não significa a participação deles no Hallel, além disso, por se tratar de um evento amplamente aberto e divulgado há a possibilidade de a presença de grupos de outras localidades estarem no evento. Mas o que devemos considerar é as devoções marianas fazem parte do cenário religioso da cidade, e que o Hallel é um espaço de compartilhamento dessa devoção. São vários os módulos que em um altar colocam a imagem de Nossa Senhora em suas mais variáveis formas. A seguir veremos algumas imagens dessa presença mariana no Hallel.

Imagem 1 - Nossa Senhora das Graças: Módulo Sim

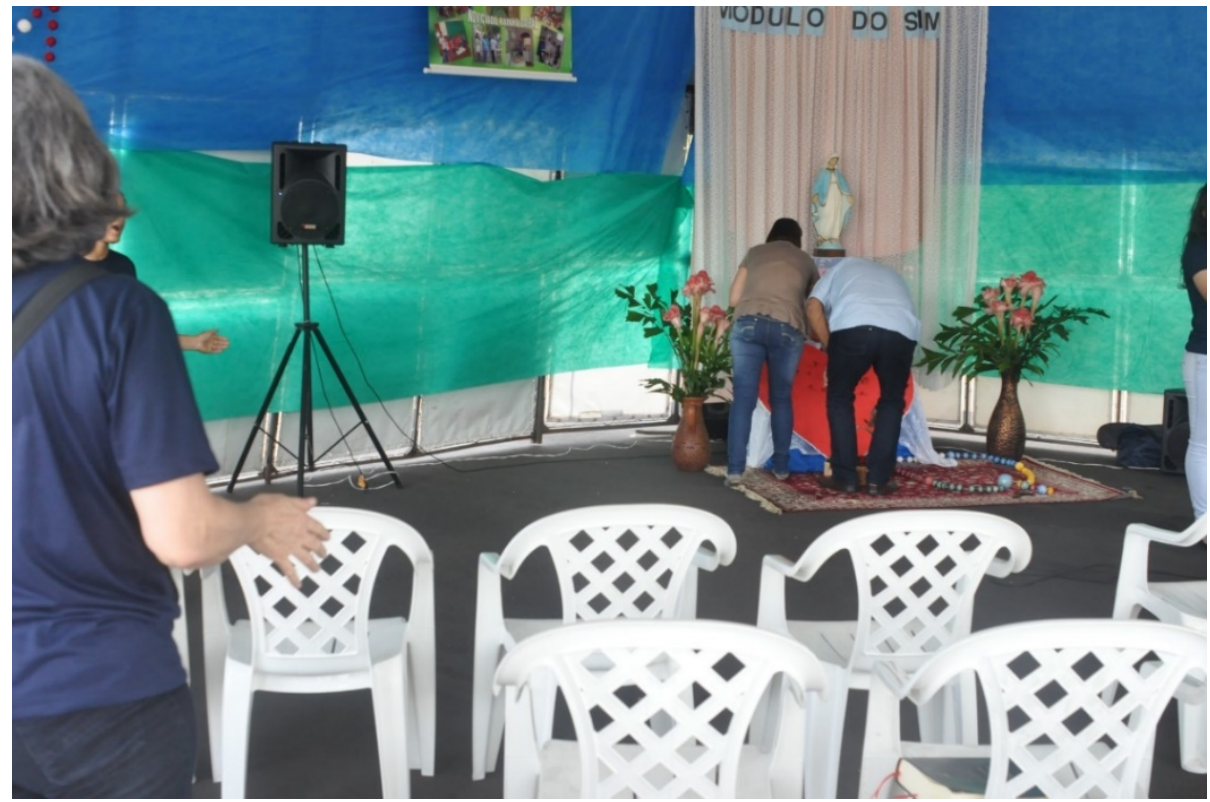

Fonte: EMERENCIANO DA SILVA, Mariane Rosa. (2015) 
Imagem 2- Nossa Senhora de Fátima: Módulo Maria

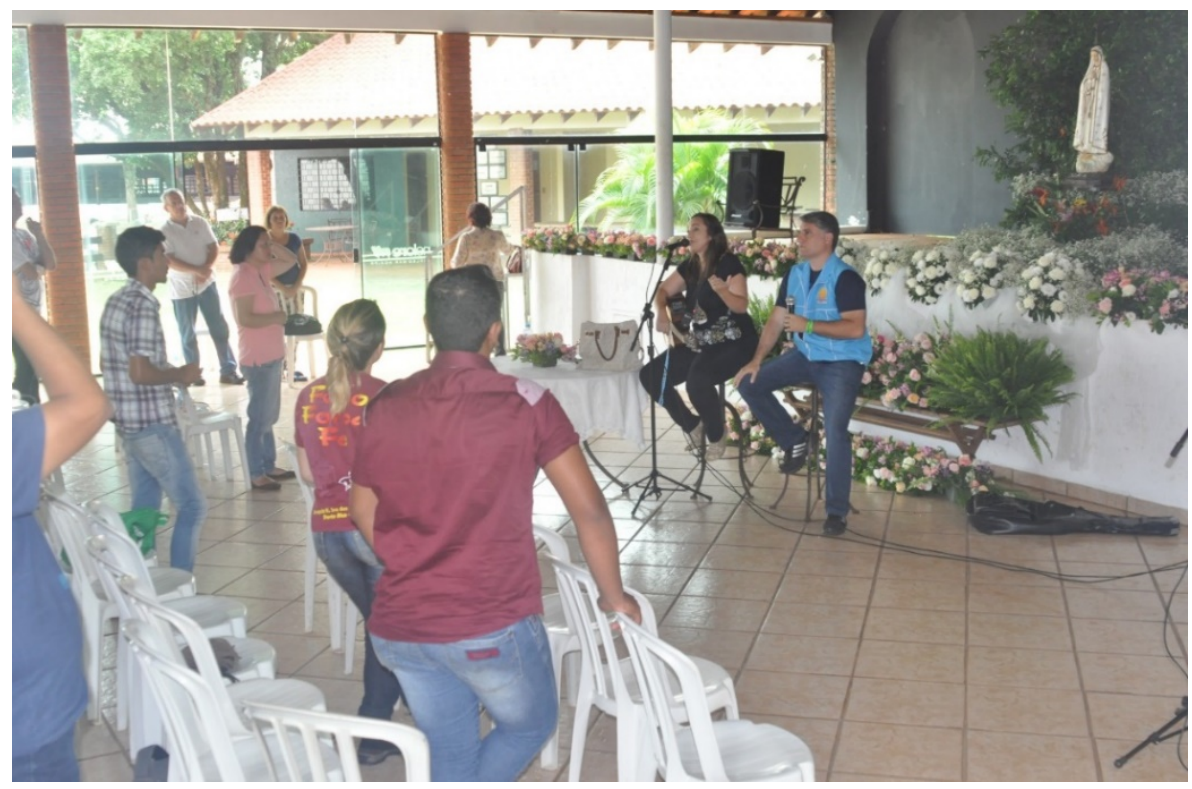

Fonte: EMERENCIANO DA SILVA, Mariane Rosa. (2015)

Imagem 3 - Nossa Senhora Aparecida: Módulo Mãos que Evangelizam

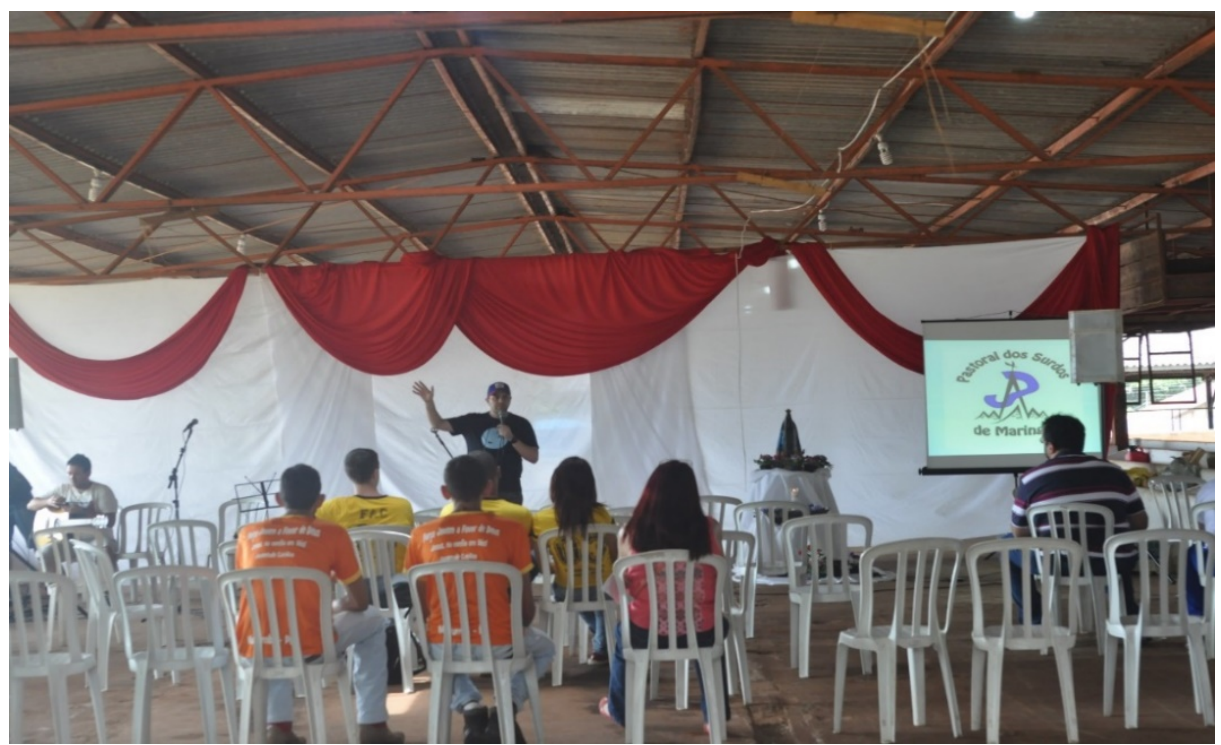


Fonte: EMERENCIANO DA SILVA, Mariane Rosa. (2015)

Imagem 4 - Nossa Senhora Aparecida: Módulo Maria (2017)

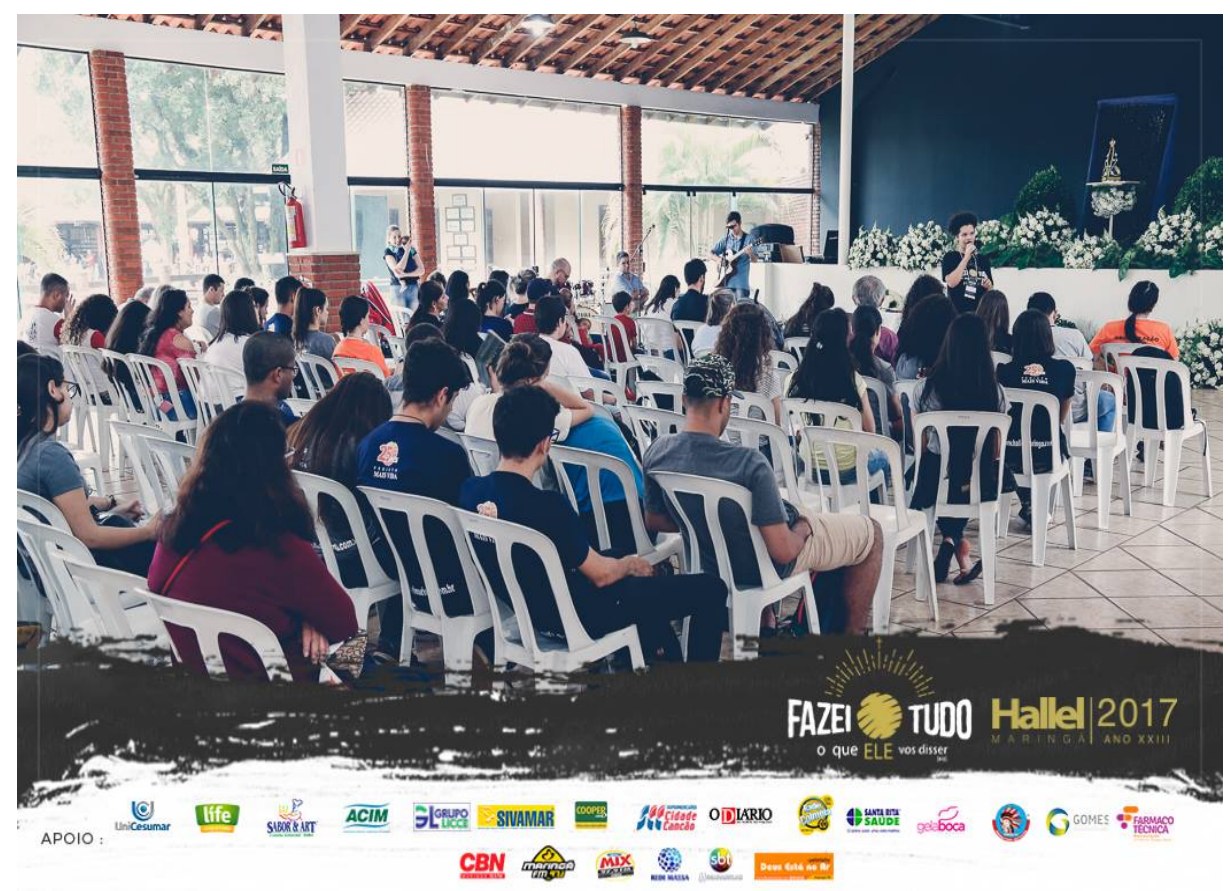

Fonte: HALLEL MARINGÁ. Disponível em: https://scontent.fmgf21.fna.fbcdn.net/v/t31.08/23157319_1868416559850339_860304900670578889_o .jpg?_nc_cat $=103 \& \_n c \_s i d=c d b e 9 c \& \_n c \_o h c=s T W r R 6 h Z 0 F g A X 9 G Y j V 2 \& \_n c$ $\mathrm{ht}=$ scontent.fmgf21.fna\&oh=df2af3181468669a68c09227eca0a35e\&oe=5F6C4F 79. Acesso em: 27 ago. 2020. 
Imagem 5 - Nossa Senhora Aparecida: Capela do Louvor 2017

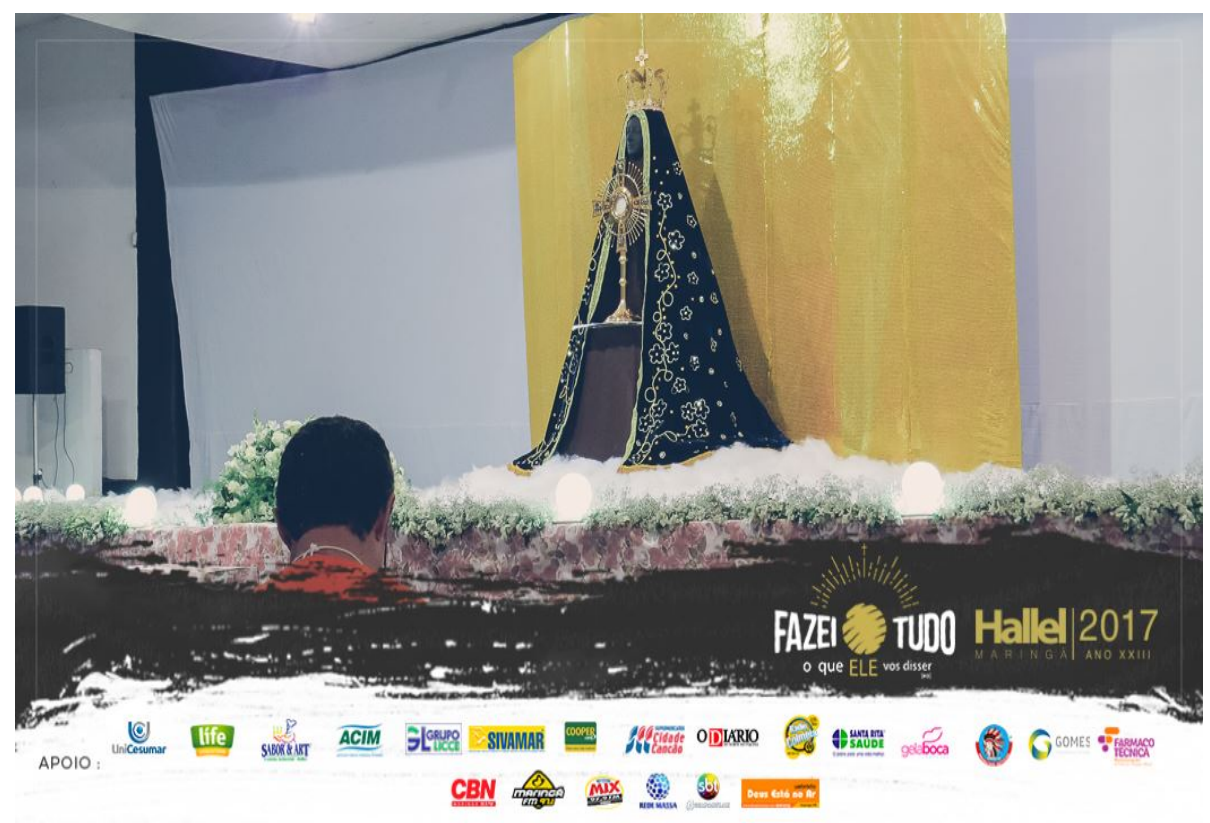

Fonte: HALLEL MARINGÁ. Disponível em: https://scontent.fmgf21.fna.fbcdn.net/v/t31.08/23213327_1869765146382147_242755653968963794_o .jpg?_nc_cat $=105 \& \_n c \_s i d=c d b e 9 c \& \_n c \_o h c=k n 2 T G o 8 S X b Y A X 9 H q B z A \& \_n c$ _ht $=$ scontent.fmgf21.fna\&oh $=$ cf7685a596662653a4387f99165d0a40\&oe=5F6C6 29D. Acesso em: 27 ago. 2020. 
Imagem 6 - Nossa Senhora de Pentecostes: Módulo RCC

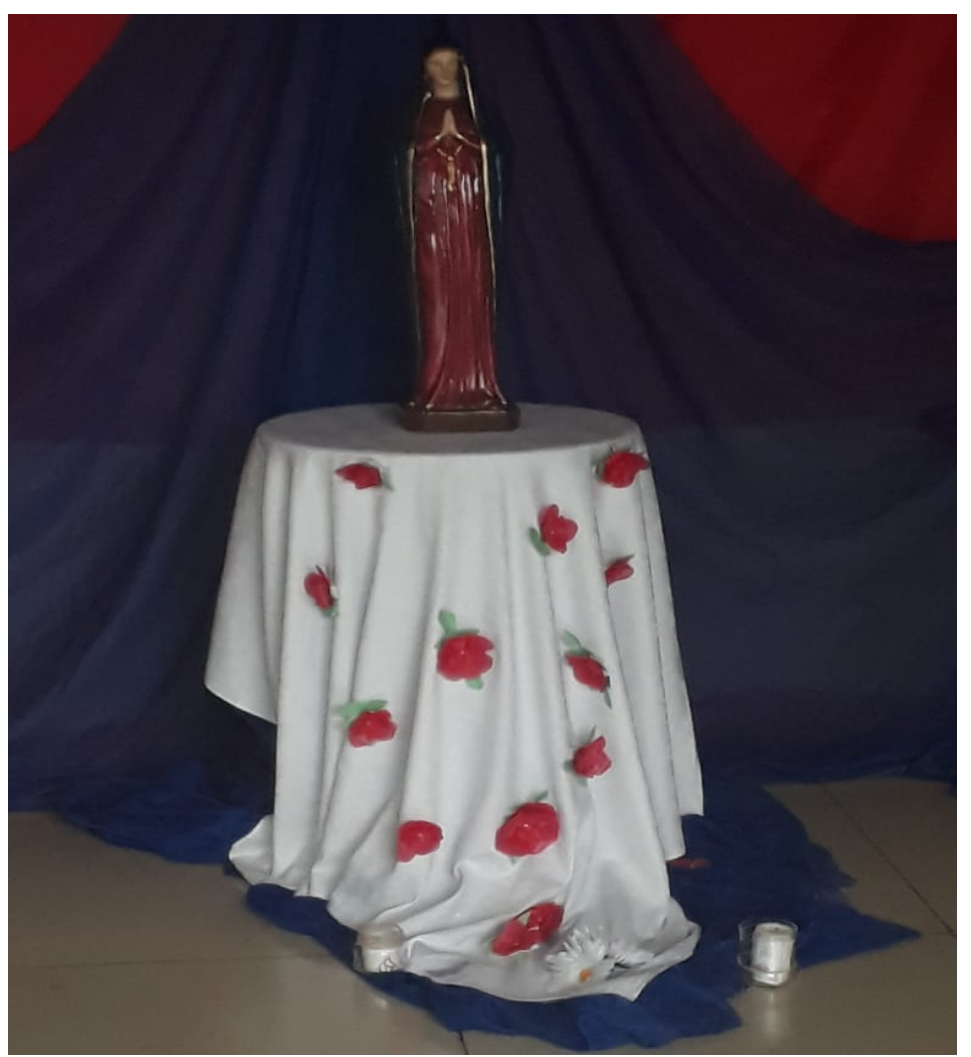

Fonte: EMERENCIANO DA SILVA, Mariane Rosa. (2015) 
Imagem 7 - Nossa Senhora de Fátima: Módulo Namoro 2019

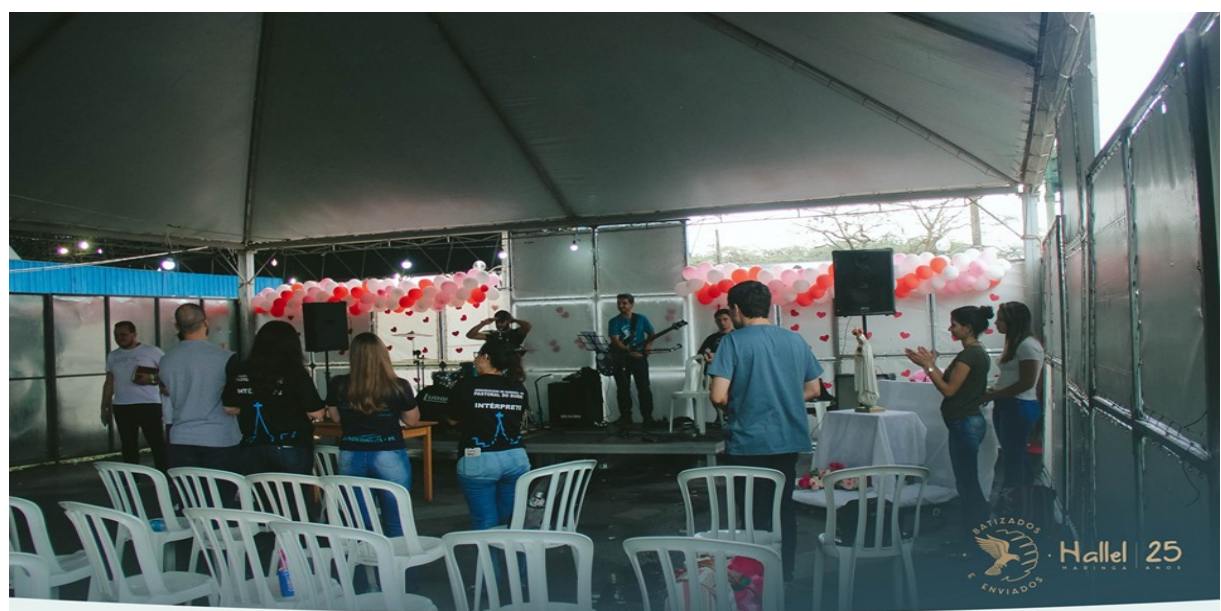

Unicesumar

Fonte: HALLEL MARINGÁ. Disponível em: https:// www.facebook.com/media/set?vanity=hallelmaringa\&set=a.323914 1282777853. Acesso em: 27 ago. 2020.

Imagem 8 - Nossa Senhora de Guadalupe: Módulo Maria

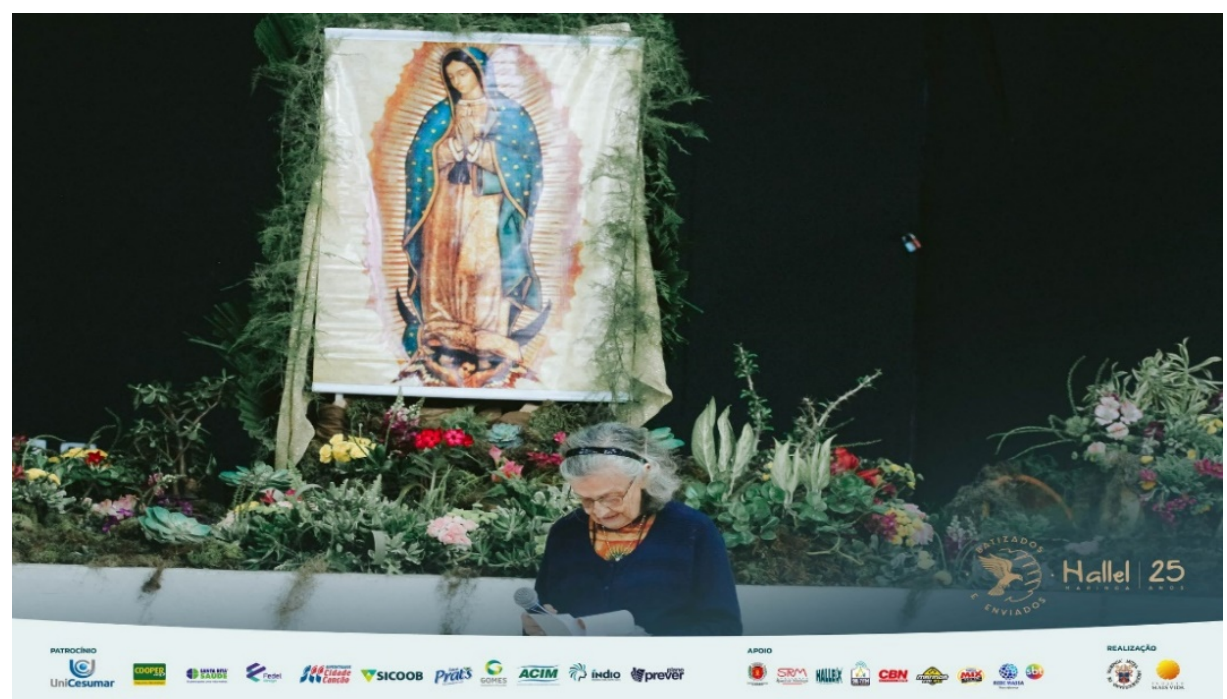


Fonte: HALLEL MARINGÁ. Disponível em: https://www.facebook.com/hallelmaringa/photos/a.3239141282777853/324 0705322621449/ Acesso em: 27/08/2020.

Para Andrade (2012, p. 242), “São inúmeras denominações de Maria cujos títulos estão associados a diferentes características da Mãe de Deus e aos fatos de sua vida". Entre esses: títulos dogmáticos, como Maternidade Divina, Imaculada Conceição, Assunção; títulos ligados aos momentos de sua vida como, Anunciação, Desterro, Dores, no caso do Hallel podemos indicar Nossa Senhora de Pentecostes na Imagem 6, com grande devoção da RCC; títulos ligados a traços de sua personalidade e dons, como, Auxiliadora, Piedade, Glória, Imaculado Coração ou das Graças como encontramos na Imagem 1, no Módulo Sim, que no ano de 2015 foi montado pelas Irmãs Missionárias do Santo Nome de Maria ${ }^{11}$; títulos ligados a santuários e imagens especiais, como é o caso da padroeira do Brasil Nossa Senhora Aparecida, nas Imagens 3, 4 e 5 observamos a presença de Aparecida, uma das imagens mais frequentes no Hallel em Maringá. No ano de 2017 devida a comemoração dos 300 anos de aparição de Nossa Senhora Aparecida a imagem dessa era marcante no evento, ao passo que como podemos observar na Imagem 5, a Mãe estava em destaque no altar com o Filho, na Capela do Louvor que é dedicada ao corpo e sangue de Cristo Sacramentado. Mas esse não foi o único ano que Nossa Senhora ocupava o espaço da Capela, em 2019 na entrada os organizadores montaram um espaço na entrada com a imagem gigante de Nossa Senhora; o último título descrito por Andrade (2012) estão ligados às

11 A Congregação das Irmãs Missionárias do Santo Nome de Maria foi fundada em 25 de março de 1920 pelo Arcebispo Dom Wilhelm Berning, bispo de Osnabrück, Alemanha, após a Primeira Guerra Mundial. É uma Congregação Religiosa, a partir de 1997 começa a ter filiação de leigos missionários. “As Irmãs Missionárias do Santo Nome de Maria herdaram o carisma missionário e a espiritualidade mariana: são chamadas a ser continuadoras do projeto evangélico iniciado por Dom Berning. Maria, associada à missão de seu Filho, é modelo [exemplo] para cada Irmã e toda a Congregação [Const. p. 12 e 20]". PBMM. Histórico. Disponível em: http:// pbmm.com.br/leigos-missionarios Acesso em: 28 jul. 2020. 
aparições, como exemplo, temos a Imagem 2, 7 e 8 com Nossa Senhora de Fátima e Guadalupe.

São distintas faces de uma mesma mulher, que é reforçada desde suas características e dons como guias e modelos para os devotos, quanto em relação a suas aparições, ou ainda os milagres atribuídos a sua imagem.

\section{A Virgem, Esposa, Mãe e Intercessora}

Durante os anos que estivemos no Hallel em pesquisa de campo, na entrada de acesso principal do evento, pela Avenida Colombo nos deparamos com duas filas, uma era para mulheres e outras para homens. Ali revistavam as bolsas, em todos os anos que entramos pela manhã no evento por volta das 7:30 horas a fila destinada para mulheres era maior. Essa presença feminina também é constatada ao conversamos com 495 pessoas entre 2016 e 2019. 60,60\% se autodeclararam do sexo feminino, enquanto 32,72\% do masculino e 6,66 não declararam. Esse público tão demarcado pelo feminino, numa religião constituída pela imagem masculina de Pai e Filho constituí também de uma construção exemplar de figura feminina a ser seguida.

Tal como nos recorda, Mircea Eliade (2010, p.85) a vida dos deuses, as figuras divinas revelam modos a serem seguidos, "O mito conta uma história sagrada", Maria ao se tornar mãe foi por meio de um ato divino, pela ação do Espírito Santo, foi a escolhida por Deus, a atribuição a maternidade e de sua conduta enquanto mulher, significa um ato sagrado, "constitui um ato real e significativo" assim, "Tudo quanto os deuses ou os antepassados fizeram - portanto tudo o que os mitos contam a respeito de sua atividade criadora - pertence à esfera do sagrado e, por consequência, participa do Ser" (ELIADE, 2010, p.85). Quando se trata de Maria, Leonardo Boff (1983) aponta que:

A tradição da fé, concentrou o feminino em Maria, mãe de Jesus. Ali viu realizadas todas as possibilidades numinosas e luminosas do feminino a 
ponto de ela ser simplesmente a Nossa Senhora: ela é virgem, é mãe, é esposa, é viúva, é rainha, é a sabedoria, o tabernáculo de Deus etc. (BOFF, 1983, p.15, grifo do autor).

Essa mesma exaltação do feminino em Maria para Boff (1979) também funciona como, “[...] mecanismo de compensação face à discriminação existente de forma generalizada na sociedade. Entretanto, esta polarização do feminino somente em Maria acaba redundando na re-afirmação daquilo que se quer exatamente superar: a supervalorização dos sexos". (BOFF, 1979, p.15-16). Essas marcas de virgem, mãe, esposa, rainha, sabedoria e tabernáculo de Deus, ainda mantém continuidades e rupturas.

A imagem da Virgem que concebe Jesus pela ação do Espírito Santo por muito se vinculou a castidade e pureza que deveria ser mantida pela mulher. Não é raro encontrar entre os grupos de jovens a concepção de "namoro santo", no qual devem guardar sua castidade até o casamento, ou ainda pregações que estão direcionadas a castidade como, por exemplo, Castidade: Guardiã do Amor Autêntico realizada por Geisy Guerra (2019), ou É possível viver na castidade nos dias de hoje? por Crislaine Janegitz (2018), ambas pregações realizadas no Módulo Namoro ${ }^{12}$. Entretanto, o percebemos é que não é uma temática voltada apenas as mulheres, e ainda não podemos perder de vista que essas são perspectivas compartilhadas de forma homogênea pelos católicos que frequentam o evento.

Outro papel que verificamos diz respeito ao de esposa, Maria ainda é percebida como a protetora do lar, mas os debates tangem uma responsabilidade reciproca entre o casal para a construção da família, ali falam sobre amor, perdão, segunda união e nulidade, são distintas visões e temáticas relacionadas aos relacionamentos conjugais. Mas sobre essa construção familiar o modelo é sobretudo o da Sagrada

\footnotetext{
12 Paralelamente as questões relacionadas a castidade, também é possível observar nesse módulo a preocupação em falar sobre como a carência poderia levar a escolhas erradas, o namoro enquanto um processo de conhecimento para o matrimônio, namoro a distância, o respeitar o outro, afetividade e sexualidade, entre outros.
} 
Família - Jesus, Maria e José, isso significa o ideal de que uma esposa tenha um filho, no qual podemos conferir nas narrativas a seguir.

Em 2014 pouco depois de sairmos da missa pela manhã estávamos no Módulo Família naquele momento uma das artistas que pregava e cantava no Hallel um testemunho dava um testemunho. Dizia ela que, na edição anterior do Hallel sofreu um aborto, mesmo assim decidiu cantar, porque acreditava que não poderia deixar de louvar e levar a palavra, Deus acolheria sua dor e ela sabia que deveria continuar sua trajetória. Naquele ano, ela havia sido abençoada dando à luz. Era uma fala sobre dor, sobre superação, sobre família e principalmente sobre confiar nos propósitos divinos, sobre ser mãe e esposa. Outra situação que vimos foi no ano de 2015, uma mulher subia ao palco do Módulo Pregadores em um momento de pregação da Irmã Zélia da Copiosa Redenção e pedia para que todos orassem por ela, que há 10 anos tentava engravidar, o local estava cheio de pessoas que direcionavam suas mãos até a mulher que esperava o milagre de ser mãe. O ser mãe, o gerar um filho é algo considerado como essencial, uma parte importante para a formação familiar.

A figura materna de Maria, do seu amor incondicional é fortemente delineada no Hallel, para esses católicos, eles também são filhos de Maria e na figura dela podem ter o colo, podem realizar pedidos para que ela interceda a Jesus.

Nossa afirmativa pode ser percebida nos títulos das palestras e pregações que se relacionam com o nome dela: Módulo de Maria: 2019 - Um ícone para a humanidade, seu nome é Maria (Diácono Cesar Ribeiro de Castro), Maria: caminho que antecipa nosso milagre (Elisia Aparecida Doles Boiko); 2018- Maria intercessora - D. Maria Vendramel, Maria, socorre nas suas maiores dificuldades (Elisa Doles Boiko - Grupo de oração Raio de Luz), Maria, mãe e protetora (Wilson Rocha). Ressaltamos que missas e terços meditados eram formas de orações recorrentes nesse módulo. Outras apresentações que enfatizam essa mãe e intercessora foi o Módulo Arte/ Dança/Teatro: 2019- Rainha do meu coração (Dança JAM -Juventude de Ação Mariana, Sarandi-PR); 2017- Filhos de Maria (Pós 
Crisma); 2016- No colo de Maria (Ministério de Dança JAD), Coração de Mãe (Ministério de Dança Servos do Pai); 2015; Restaurados pela intercessão de Maria (Ministério de Artes e Sentinelas do Amanhã). O que percebemos é que o que tangencia com maior intensidade é a Mãe que opera milagres, que se sacrifica, que liberta.

Recordamos que em 2017, antes um pouco do sol se pôr, embora tivesse movimento entre os módulos, eles estavam em processo de encerramento com as pessoas se encaminhando até o Palco Central para os shows principais. Então, o Módulo de Maria nos chamou atenção, o local tinha muita gente e várias pessoas estavam saindo com rosas brancas em suas mãos, o que nos levou a ver o que estava acontecendo no módulo. À medida que as pessoas iam saindo, nós íamos entrando. Naquele ano a imagem de Nossa Senhora Aparecida estava ao centro, ano de celebração dos 300 anos de sua aparição como podemos observar na Imagem 4. Uma enorme quantidade de rosas brancas enfeita o ambiente, numa espécie de altar. Eram aquelas rosas que os fiéis estavam retirando, pegando por si, ou das mãos dos organizadores do módulo. Algumas pessoas saiam com várias rosas, com doze, quinze rosas, demostrando um apresso por tê-las consigo. Majoritariamente eram mulheres e mulheres mais velhas, havia sim um público de outras idades como crianças, jovens, homens, entretanto, eram mulheres que predominavam. Foi quando repousamos nosso olhar em uma mulher, sua presença saltava aos nossos olhos, se destacava, pois parecia estar indo em contra ponto ao restante do público que tanto ansiavam pelas rosas e queriam ir para o show, não, ela não, com um bebê no colo ela tinha um caminhar preciso, objetivo e não buscava as flores. A mulher parou diante de Nossa Senhora, enquanto uma das organizadoras do módulo pega a imagem de Maria e tenta aproximar a imagem até a mulher, enquanto a mãe tenta aproximar a criança que estava em seu colo até a imagem de Nossa Senhora. Inicialmente, aquilo nos causa ansiedade pois a mãe inclinava e estendia para cima o bebê até a imagem porque estava em um local elevado, a sensação era de que a criança ou a imagem poderiam cair a qualquer momento, até que ela 
consegue tocar o bebê em Nossa Senhora. A mãe ao virar-se em ângulo que podíamos ver sua face, víamos que estava muito emocionada, ao baixarmos o nosso olhar até o bebê que era bem novinho havia um corte na parte superior de sua cabeça, no cabelo raspado. Nesse momento, a clareza sobre essa cena tomou-nos a mente, era uma graça alcançada ou um pedido. A mãe podia estar cumprindo uma promessa e em gratidão a cirurgia bem-sucedida, ou a situação que sua criança havia passado levava-a até Nossa Senhora, ela precisava agradecer. A fé, o caminhar firme e a crença no poder de Maria eram reais para aquela mãe. Não sabemos se a organização sabia sobre as intenções da mãe, era visível o esforço desses para que o ato fosse realizado também. Não se trata apenas de uma imagem, é um momento mágico, trata-se de um momento de fé, devoção, de uma crença que marca situações da vida daquela mãe, que pedia a outra mãe que intercedesse por seu filho (a). Essa cena foi após a Missa de Com sagração e renovação dos votos à nossa Senhora, celebrada pelo Padre Rodrigo Guietierrez Stabel. A narrativa que acabamos de descrever nos traz reflexões sobre como,

a imagem mítica de uma mãe universal, sempre pronta a zelar por seus filhinhos [...], tem raízes profundas na nossa cultura. As querelas em torno do culto mariano vão além de uma marca de diferenciação. Está em jogo também a abdicação ou não da imagem da mãe mítica, ao que nos parece, da feminilidade e do feminino como parte integrante da constituição universal, da possibilidade do ser humano de buscar um fim que não seja tão esmagadoramente centralizado numa figura masculina, e mais, da possibilidade do humano como algo esplendoroso (PRANDI, 1998, p. 142).

Desse modo, concluímos que ao considerar que o Hallel é um espaço de práticas católicas em Maringá, de experiência religiosa e o reconhecimento do sagrado na festa, Maria é a Virgem, a Esposa, o modelo, seguidora de Jesus e principalmente a Mãe acolhedora, paciente, benevolente e intercessora, estabelecendo um fio condutor na imagem de mãe e de feminino para os católicos. 


\section{Referências}

ANDRADE, Solange Ramos de. Devoções e santuários Marianos na História do Paraná. Revista Angelus Novus, v. 3, p. 239-260, 2012.

BOFF, Leonardo, O.F.M. O rosto materno de Deus: Ensaio interdisciplinar sobre o feminino e suas formas religiosas. Petrópolis: Editora Vozes, 1983.

ELIADE, Mircea. O sagrado e o profano. São Paulo: editora WMF Martins Fontes, 2010.

EMERENCIANO DA SILVA, Mariane Rosa. Hallel de Maringá 2016- $22^{a}$ edição, $2^{\circ}$ dia. Parque de Exposição Francisco Feio Ribeiro. Maringá-PR, 2016. Trabalho de campo. (História, Universidade Estadual de Maringá, Maringá, PR), 04 de dez. de 2016.

EMERENCIANO DA SILVA, Mariane Rosa. Observação Hallel de Maringá 2014-20 edição. $2^{\circ}$ dia. Parque de Exposição Francisco Feio Ribeiro, Maringá-PR, 2014, Trabalho de campo. (História, Universidade Estadual de Maringá. Maringá, PR). 09 de nov. de 2014.

EMERENCIANO DA SILVA, Mariane Rosa. Observação Hallel de Maringá 2015, - $21^{a}$ edição, $2^{\circ}$ dia. Parque de Exposição Francisco Feio Ribeiro, Maringá-PR, 2015. Trabalho de campo. (História, Universidade Estadual de Maringá. Maringá, PR). 08 de nov. de 2015.

EMERENCIANO DA SILVA, Mariane Rosa. Observação Hallel de Maringá 2017- 23a edição $2^{\circ}$ dia. Parque de Exposição Francisco Feio Ribeiro, Maringá-PR, 2017. Trabalho de campo. (História, Universidade Estadual de Maringá, Maringá, PR), 05 de nov. de 2017.

EMERENCIANO DA SILVA, Mariane Rosa. Observação Hallel de Maringá 2018- $24^{a}$ edição, $2^{\circ}$ dia. Parque de Exposição Francisco Feio Ribeiro, Maringá-PR, 2018. Trabalho de campo. (História, Universidade Estadual de Maringá, Maringá, PR), 30 de set. de 2018.

HALLEL MARINGÁ 2017. Programação do Hallel Fazei tudo o que Ele voz disser. Maringá-PR, 2017, Ano XXIII.

HALLEL MARINGÁ 2018. Programação do Hallel Em Cristo somos todos irmãos. Maringá-PR, 2018, Ano XXIV. 
HALLEL MARINGÁ 2019. Programação do Hallel Enviados e Batizados. Maringá-PR, 2019, Ano XXV.

HALLEL MARINGÁ, 2015. Programação do Hallel Eis me aqui envia-me. Maringá-PR, 2015, Edição XXI.

HALLEL MARINGÁ, 2016, Programação do Hallel Sementes de uma nova geração. Maringá-PR, 2016, Ano XXII.

PRANDI, Reginaldo. Um sopro do Espírito: a renovação conservadora do catolicismo carismático. 2. ed. São Paulo: Editora da Universidade de São Paulo: Fapesp, 1998.

SERAFIM, Vanda Fortuna. Observação Hallel de Maringá 2017- $23^{a}$ edição, $2^{\circ}$ dia. Parque de Exposição Francisco Feio Ribeiro. Maringá-PR, 2017. Trabalho de campo. (História, Universidade Estadual de Maringá, Maringá, PR). 05 de nov. de 2017. 